\title{
Back to the basics: the disparity between footprints and profits
}

\author{
Petar Sabev Varbanov ${ }^{1}$
}

Published online: 9 May 2020

(c) Springer-Verlag GmbH Germany, part of Springer Nature 2020

Nearly 2 years ago, several editors wrote an editorial for this journal (Varbanov et al. 2018), centred around the observation that nearly two-thirds of the energy from primary sources is wasted on its way to the final products and services. That observation is still valid-indicating that the energy structures of the World economies have not evolved substantially towards higher efficiency.

Various goods and services can be ordered over the internet from all over the world. In the research aiming to improve the performance of process systems, the structure of energy consumption and emissions of the entire supply chains and the lifecycles of their products should be analysed.

If one considers the whole planet Earth as one large ecosystem, it becomes clear that all material streams form closed loops. Each product supply chain starts with extracting primary raw materials from natural storages. This also includes sourcing fossil fuels and water. The further steps of the supply chains include transportation and processing operations which release greenhouse gases, aqueous emissions and other waste streams (Fan et al. 2018). Eventually, these waste streams make their way to natural storages.

In the case of aqueous emissions, by natural paths, the streams flow into water basins from which water as a raw material is taken. That makes a complete water cycle. In a similar way, air taken from the atmosphere is partially returned to the atmosphere with flue gases and other gaseous output streams. Additionally, various liquid and solid materials are deposited to natural storages. It has to be stressed that these material cycles are not closed perfectly. The contents of the initial materials get misdirected and transformed by the supply chain activities, so the materials released into the environment cause pollution.

Petar Sabev Varbanov

varbanov@fme.vutbr.cz

1 Sustainable Process Integration Laboratory-SPIL, NETME Centre, Faculty of Mechanical Engineering, Brno University of Technology-VUT Brno, Technická 2896/2, 61669 Brno, Czech Republic
The dominant pattern for energy flow through the Earth as a system develops through cascading with quality degradation. Electromagnetic energy from the Sun falls on the Earth surface and flows through the ecosystems and human activities, gradually reducing the quality and dissipating. This pattern, however, occurs only for renewable energy which comes from the Sun and only to some extent.

Any fossil fuels used to power processes and activities in supply chains feature a mixed pattern. Fossil fuels are materials taken from natural deposits. Their use is subject to the pollution effects of material cycles. On the other hand, the heat produced from fuel combustion follows the pattern of cascading and degradation, outlined above.

Consequently, the pollution effects of supply chains can be considered as having two components. The first comes from the usage of raw materials for products. The second comes from the use of fossil fuels. It can be seen that almost all stages of supply chains contribute to pollution. This includes transformation, packaging, production, as well as transportation stages. Therefore, the longer the supply chain is, the more stages it involves, the higher is the resulting pollution.

Having this background, a few facts should be discussed. The statistical services of the European Union and the USA publish the structure of emissions by sectors. The values of greenhouse gas emissions from the sectors for 2017 are distributed almost equally among each other, in the range between 25 and $35 \%$ among industrial, residential and transportation sectors (European Commission 2020). The agricultural sector doesn't lag too much behind. Unfortunately, figures for International transport are not easy to obtain but even based on the quoted figures, it can be reasoned that goods sourced and delivered by shorter supply chains, from local sources, are likely to produce much lower footprints than supply chains sourcing and producing goods at a distance, and importing them. And yet, in the modern global world, importing products from thousands of miles or km away is very often cheaper and more profitable than to produce them and deliver them locally. 
This disparity between emissions and cost reveals the need to research the reasons causing more polluting supply chains to be more profitable. It leads to the question of what measures are necessary to bring footprints and costs in an agreement?

To answer this question is far from trivial, and it needs well-reasoned assessments (Fan et al. 2020). Without appropriate studies with quantification of the results, the experts will not have sufficient reasons to convince the public and the decision-makers in need for changing the policies and business practices. And without changing policies and practices, there can be no improvement to the quality of life or bringing our societies to a sustainable development trajectory.

\section{References}

European Commission (2020) Shedding light on energy on the EU: how are emissions of greenhouse gases by the EU evolving? In:
Shedding light on energy on the EU. https://ec.europa.eu/euros tat/cache/infographs/energy/bloc-4a.html. Accessed 26 Apr 2020

Fan YV, Perry S, Klemeš JJ, Lee CT (2018) A review on air emissions assessment: transportation. J Clean Prod 194:673-684

Fan YV, Klemeš JJ, Ko CH (2020) Bioenergy carbon emissions footprint considering the biogenic carbon and secondary effects. Int $\mathrm{J}$ Energy Res. https://doi.org/10.1002/er.5409

Varbanov PS, Sikdar S, Lee CT (2018) Contributing to sustainability: addressing the core problems. Clean Technol Environ Policy 20:1121-1122. https://doi.org/10.1007/s10098-018-1581-8

Publisher's Note Springer Nature remains neutral with regard to jurisdictional claims in published maps and institutional affiliations. 